\title{
LES POESIES POPULARS \\ CATALANES DE LA TRADUCCIÓ \\ DEL DECAMERON (SANT CUGAT \\ DEL VALLÈS, 1429)
}

Josep Romeu i Figueras

\section{LA TRADUCCIÓ CATALANA DEL DECAMERON, DE 1429}

El colofó del còdex que conté aquesta traducció és redactat sota els següents termes: «Fo acabada la present translació dimarts, que comptàvem $\cdot \mathrm{V}$. dies del mes de abril en l'any de la fructificant Incarnació del Fill de Déu M CCCC XXVIII, en la vila de Sant Cugat del Vallès».

El manuscrit, procedent de la llibreria de Miquel Victorià Amer, pertanyé a Isidre Bonsoms i Siscart i, a la seva mort, passà, entre 1914 i 1915, a la Biblioteca de Catalunya, on actualment duu el número 1716. Caroline Brown Bourland descriví per primer cop, el 1905, el manuscrit, aleshores ja en poder d'Isidre Bonsoms ${ }^{1}$, i Jaume Massó Torrents n'efectuà la transcripció, que publicà, amb una

1 C.B. BOURLAND, «Boccaccio and the Decameron in Castilian and Catalan Literatures, Revue Hispanique XII (1905), pp. 25-32. Del mateix any és una referència de $\mathrm{M}$. SCHIFT al manuscrit català dins aLa bibliothèque du Marquis de Santillana (Paris 1905, Bibliotheque de l'École des Hautes Études 153), pp. 354. 
introducció, el $1910^{2}$ i que despertà un fort interès entre els ambients erudits. Ramon d'Alòs-Moner edità, uns anys després, tres novel-les de l'obra, establint el text damunt el manuscrit ${ }^{3}$. Una nova edició de la vella traducció fou començada, i tot seguit abandonada, per «Els Nostres Clàssícs», que, en els dos únics volums publicats, reprodueix les jornades I i II, segons el text de Massó 4 . Germà Colon té enllestida, ja fa anys, la terminació d'aquesta edició per a la mateixa col-lecció, amb transcripció directa de l'original manuscrit $i$ amb l'estudi filologic pertinent ${ }^{5} \mathrm{i}$ és molt lamentable que no aparegui d'una vegada a la llum pública una edició així, sens dubte de la màxima solvència.

La problemàtica d'aquesta traducció ha anat precisant-se al llarg de les aportacions fetes pels estudiosos que se n'han ocupat. En la seva descripció externa del manuscrit, ja citada, C.B. Bourland remarca, entre altres extrems, les dues parts que, des del punt de vista

2 Johan BoccaCI, Decameron. Traducció catalana publicada, segons l'únic manuscrit conegut (1429), per J. MAssó TORRENTS, The Hispanic Society of America, New York 1910, «Bibliotheca Hispanica». L'existència d'aquesta transcripció moderna, la coneixia M. MENÉnDEz PEL.AYO, que la utilitzà, amb informació i textos facilitats per J. Massó i I. Bonsoms, als seus Origenes de la novela II Madrid 1907, NBAE 7, pp. VI-IX. I. BONSOMS i SISCART donà a conèxer alguns fragments de l'esmentada transcripció a la seva «Introducción a la lectura de unos fragmentos de las traducciones catalanas de la "Fiametta" y del "Decamerone" de Boccaccio, ambas anónimas y hechas en el siglo xV”, Boletín de la Real Academia de Buenas Letras de Barcelona IV 1907-1908, pp. 382-399. Existeix una reproducció textual i fraudulenta de l'obra de Massó indicada, titulada Joan Bocaccio, Decameron. Traducció catalana publicada segons l'únic manuscrit conegut (any 1429), AHR, Barcelona 1964.

${ }^{3}$ G. Boccaccio, Dell antica versione catalana del Decameron, brani scelti da R. d'Alós-MONER, Roma 1915, «Testi Romanzi», diretti da E. MONACI, 34; novel-les V, 9; VI, 4, X, 7.

4 Joan Boccaccio, Decameró. Versió catalana de 1429. Introducció de Carles Riba. Dos volums apareguts, Barcelona 1926 i 1928, ENC 8 i 17. La introducció fou reproduïda a C. RIBA, Obres completes II, Edicions 62, Barcelona 1967, pp. 653-661.

${ }^{5}$ Segons que exposa l'esmentat estudiós al seu treball $\&$ Un aspecte estilístic de la traducció catalana del Decameron», dins Interlinguistica. Sprachvergleich und Obersetzung. Festschrift zum 60. Geburtstag von Mario Wandruszka, Max Niemeyer Tübingen [1971], pp. 648-660; veg. pp. 648-649. 
paleogràfic, presenta aquell, l'una fins a la novel-la $\mathrm{V}, 8 \mathrm{i}$ l'altra fins al final, caracteritzades per dos tipus de lletra i procediments diferents i per haver estat escrites, respectivament, a caixa plena i a doble columna; la identificació de la novel-la X, 10, amb la traducció de la Griselda de Bernat Metge; la presència de quatre cançons catalanes al final de les jornades I, V, VI i VII en substitució de les italianes corresponents; les molt poques omissions de l'original, i les addicions del final d'algunes novel-les. En apèndix publica les esmentades quatre cançons i transcriu les peces breus que Dioneo canta a la fi de la jornada $v$.

A la introducció de la seva edició del Decameron català ja esmentada, Massó Torrents remarca l'interès de l'obra en les relacions culturals entre Itàlia i Catalunya. Partint de detalls materials del manuscrit, pensa que aquest degué formar part de la biblioteca de Gaspar Sánchez Muñoz, de Terol, que havia heretat part dels llibres de Gil Sánchez Muñoz, successor de Benet XIII a Peníscola, de manera que n'infereix que el còdex pertangué a la biblioteca d'aquest darrer. Fa una descripció del manuscrit, basant-se en la de Bourland, i creu trobar indicis de mallorquinismes en la segona part del còdex, que suposa que serien deguts a «un monjo mallorquí» que hauria treballat a Sant Cugat del Vallès. Formula la hipòtesi que es poden identificar escrivents i traductors, de manera que la versió es deuria a dos traductors diferents. Assenyala uns quants italianismes del text, i valora la «fluència» $\mathrm{i}$ la «facilitat» de la traducció, feta sense esforç aparent $i$ amb un estil «senzill», el bon ús de la llengua $\mathrm{i}$ «la frase ben catalana, el període arrodonit», encerts que compensen alguna escadussera deficiència del text, imputable, d'altra banda, als procediments de traducció del temps. Creu que ens trobem davant, no pas d'una traducció, sinó d'una «adaptació», com acrediten la presència de les quatre cançons catalanes en substitució de les italianes i les «catalanitzacions» d'alguns detalls, com és ara el fet de suplir spagnuolo per català, les precisions que s'hi fan quan la narració s'escau en indrets catalans, i un seguit de proverbis o aforismes als quals fa al-lusió. S'ocupa de les fonts catalanes de la novel-la X, 7 , en el sentit que l'anècdota es troba ja en la crònica de Desclot, i subratlla, com ja havia fet Bourland, que la novel-la X, 10, final de l'obra, és el text de la Griselda traduida per 
Bernat Metge damunt la versió llatina que Petrarca féu de la novel-la de Boccaccio 6 . Cal notar que les pàgines de Massó han constituit durant molts anys la font primordial sobre el Decameron català.

Una altra aportació important és la deguda a Mario Casella?, orientada, no pas a la història externa del manuscrit, sinó a la cultural de l'obra i a la crítica i el seu sentit. Casella parla sempre d'un sol traductor, i es proposa de demostrar que aquest comprèn profundament l'obra de Boccaccio i s'esforça a anostrar-lo en un català pur i matisat. El Decameron català «non è traduzione letterale», afirma, sinó «traduzione e interpretazione», una adaptació de l'original, com es desprèn de l'anàlisi de la fidelitat de l'estil i la narració. Segons aquest crític, el traductor català s'enfrontava a una prosa escrita en una retòrica més complexa que la que li era habitual, a pesar del bon nivell cultural que posseïa, d'on les males lectures i els errors de traducció detectables. Nota, així mateix, la tendència a substituir les subordinades per les coordinades i a evitar l'hipèrbaton, a alleugerir els períodes massa llargs, a simplificar i a suplir l'estil indirecte pel directe. Quant a la narració pròpiament dita, remarca diverses modificacions, com poden ésser els abreujaments, les supressions, la voluntat de concretar i d'adaptar, les moralitzacions, les glosses finals, els proverbis i les frases fetes com a recursos per a l'anostrament i l'adaptació, algunes males interpretacions que dilueixen el sentit irònic de l'original i, per contra, intromissions personals que introdueixen nous matisos d'aquest sentit. A més, Casella parla sovint de l'ambient a què pertanyia el traductor, que considera laic i refinat a causa dels seus contactes evidents amb la cultura italiana.

La introducció de Carles Riba a l'edició d' «Els Nostres Clàssics», al marge del seu valor com a esplèndida peça crítica, és una

${ }^{6}$ Com ja hem dit, M. MENENDEZ PEL AYo, Orígenes de la novela, recull una part de les dades apuntades, que li foren trameses per Massó i Bonsoms.

7 .La versione catalana del Decameron*, Archivum Romanicum IX, 1925, pp. 387-412, reproduit a M. CASELLA, Saggi di letteratura provenzale e catalana. Racolti da G.E. Sansone, Adriatica Editrici, Bari 1966, «Biblioteca di Filologia Romanzas 1, pp. 244-281. 
bona síntesi de les pàgines de Massó Torrents i del treball de Mario Casella. D'aquest darrer reté la idea que el Decameron català és una adaptació plenament incardinada en el món de la cultura catalana d'aleshores, fins al punt de constituir un exemple rellevant de l'assimiliació de la mentalitat renaixentista italiana a l'època del trasllat.

Dos historiadors de la literatura catalana s'han ocupat breument de la traducció catalana. L'un, Jordi Rubió i Balaguer ${ }^{8}$, pensa que el manuscrit havia pertangut a la biblioteca de Benet XIII. L'altre, Martí de Riquer ${ }^{9}$, considera, com Massó, que els traductors foren dos, remarcant, però, que no consta que fossin monjos. Opina que els errors de la traducció catalana poden derivar de la còpia italiana del Decameron damunt la qual es basa, i que els italianismes són menys abundosos que en la versió de la Divina Commedia feta per Andreu Febrer.

Germà Colon, en el treball citat a la nota 5, cenyit a l'estudi d'un aspecte estilístic concret de la traducció catalana, que l'autor qualifica de constant de procediment retòric del traductor, opina que es pot sostenir que aquella versió, exceptuant-ne la novel-la X, 10, és obra d'un sol traductor, i que el manuscrit ha d'ésser la còpia d'un antígraf. Refusa els pretesos «mallorquinismes» al-legats per Massó i subratlla que no es pot demostrar que els dos copistes haguessin estat monjos, ans podem conjecturar versemblantment que no ho foren 10 .

En un bon treball de síntesi i de recerca, Lola Badia" ${ }^{11}$ arriba a diverses conclusions que podem resumir com segueix. Quant a la historia de la transmissió del manuscrit, demostra que aquest no pogué pertànyer a la biblioteca del papa Luna, Benet XIII, i remarca, d'altra banda, que consta que la família dels Sánchez Muñoz adqui-

8 Literatura catalana, dins Hisioria general de las literaturas hispánicas III, Barcelona 1953, pp. 791-792.

${ }^{9}$ Historia de la literatura catalana II, Barcelona 1964, pp. 467-470.

10 G. CoLon, op. cit., p. 660, nota 13, addueix la recensió de Pere Bohigas de l'obra de J. RuBIO I BALAGUER, «De l'Edat Mitjana al Renaixement», Barcelona 1948, dins Estudis Romànics, III (Barcelona 1951-1952). pp. 311, nota 2, on apunta que el fet que el colofó faci referència a la vila de San Cugat del Vallès pressuposa que el lloc de la còpia no fou el monestir.

11 «Sobre la traducció catalana del Decameron de 1429m, Boletín de la Real Academia de Buenas Letras de Barcelona XXXV (1973-1974), pp. 69-101. 
rí, entre 1429 i 1484, una versió catalana del Decameron, que versemblantment es pot identificar amb l'actualment conservada a la Biblioteca de Catalunya, manuscrit 1716, i que hom en perd la pista entre 1530, quan Gaspar Sánchez Muñoz féu inventari dels seus béns, i el començament del nostre segle, quan Miquel Victorià Amer apareix com a posseìdor del còdex. Considera ben justificable la tesi d'un sol traductor i de dos copistes, amb hàbits d'escriptura diferents. Posa en relleu el fet que, en contraposició amb altres obres de Boccaccio, no hi ha constància de l'existència de cap altra traducció del Decameron a l'edat mitjana a Catalunya, ni del text original en toscà. La «història solitària» i la singularitat del text català, l'autora les relaciona amb les remarques de Vittore Branca sobre la difusió i transmissió del Decameron a Itàlia abans de la primera meitat del segle XV, segons les quals aquella difusió i transmissió estan profundament vinculades amb ambients burgesos i mercantils, molt actius en les seves relacions professionals i viatgeres, entusiastes d'aquesta obra boccaccesca, tal com ho eren els mateixos copistes, escrivents d'excepció i persones de les més diverses condicions i professions, que es convertiren en amanuenses d'ocasió per satisfer el desig personal de posseir aquell text de moda, un llibre de lectura amena i agrađós al lector comú, mentre que constata una singular fredor envers ell als ambients més literaris, més refinats, més imbuïts i preocupats pel fet literari i cultural pre-renaixentista i proto-humanístic. D'aquí que Lola Badia, justificant les seves hipòtesis amb raonaments convincents aplicats a la versió catalana, pensa que, «de fet, només algú pertanyent a un estament mercantil en contacte amb els col-legues toscans que s'entusiasmaven amb aquella obra aparentment extraliterària podia ferse càrrec del seu valor i trasplantar-la al nostre país», al marge dels «erudits» o «humanistes» de la cancelleria reial o, d'altra banda, dels ambients pietosos i medievalitzants de l'entorn de la reina Maria. L'autora, per mitjà d'una anàlisi parcial feta en quatre cales del llibre, arriba a unes conclusions estilístiques que no modifiquen les aportades per Casella i Colon. En primer lloc, al nivell lèxic a penes ha trobat italianismes en el sentit de mots absolutament aliens a la llengua catalana incorporats per calc semàntic, i remarca que sí que hi ha trobat mots d'origen italià ja documentats a Catalunya i cons- 
truccions de mots catalans fetes a la italiana. Són freqüents els italianismes per transliteració. La traducció és feta només en una mínima part pel procediment medieval del calc i la transliteració. El text presenta a tots nivells diferències notables respecte a l'original. Pel que fa al nivell sintàctic, l'autora assenyala les característiques següents: ús abundós de copulatives i relatives per evitar construccions de participi de present o de gerundi, o frases amb participi de passat amb valor d'ablatiu absolut llatí; de tota manera, el traductor no sempre simplifica la sintaxi, tot potenciant les construccions paratàctiques; sovint desfâ hipèrbatons i elimina incisos, bé que d'altres vegades, en canvi, hi introdueix complicacions sintàctiques; evita constantment la construcció d'infinitiu a la llatina, que substitueix pel que declaratiu sempre que pot; sovint, quan desmunta els períodes complexos de l'original, la traducció perd cohesió sintàctica, fins al punt que, de vegades, el sentit resta més o menys clar, sense que el text resisteixi una anàlisi sintàctica; alguns cops sembla com si el traductor hagués entès la informació fonamental de l'original, però que no sabés manejar tots els fils de la sintaxi del període. Quant als canvis introduits pel traductor, Badia remarca la llibertat, sovint arbitrària, d'afegir-hi explicacions suposadament aclaridores de l'original, i també la tendència a ampliar o a abreujar determinats fragments, a voltes obeint a alguns motius logics que justifiquen aquests canvis i retocs; hi ha simplificacions justificades $i$ addicions d'elements personals del traductor, no sempre afotunades; no es pot generalitzar que el traductor comprengui i reprodueixi els recursos retòrics de l'original, que més aviat li passen per alt que no pas assoleix de traslladar. Nota, finalment, que una de les qualitats generalment atribuïdes al Decameron català és la musicalitat, per tal com la prosa flueix amb una perfecta sonoritat catalana, i que, per contra, també és un fet reconegut que el nostre traductor no sempre és capaç de desentrellar les dificultats dels períodes de l'original, de manera que algunes vegades la construcció sintàctica de les frases catalanes no és pas correcta; i creu haver trobat una explicació d'aquest contrasentit aparent —prosa musical però mal construïda - en la utilització, per part del traductor, de clàusules mètriques i versos intercalats en la prosa, dels quals ofereix i comenta uns quants casos. 
Un fenomen evident de la catalanització, de l'anostrament, del text boccaccià verificada sistemàticament pel traductor català del text de 1429, el constitueixen, com ja ha estat remarcat, les quatre poesies en la nostra llengua que substitueixen les italianes de l'original i que apareixen al final de les jornades I, V, VI i VIII ${ }^{12}$, mentre que a les restants no fou copiada cap i el copista deixa, al final, un espai en blanc, llevat de la jornada IX, i les breus composicions que Dioneo proposa de cantar en finalitzar la $\mathrm{V}^{13}$.

De les quatre primeres poesies indicades, dues són de caràcter culte: Eu am tal que és bo e bel, del final de la jornada I, i No puch guarir de la nafra preyon, al final de la jornada v. La primera, incompleta, ja que només reprodueix els tretze versos inicials, es troba, versemblantment sencera, també al cançoner Vega-Aguiló, manuscrit 7 de la Biblioteca de Catalunya, on porta la rúbrica $L a$ Reyna de Mallorques, indicadora de l'autora del poema, la qual hom identifica amb Constança, filla d'Alfons el Benigne, germana de Pere III el Cerimoniós i primera muller de Jaume III de Mallor$\mathrm{ca}$, morta el $1346^{14}$. L'altra és anònima i està constituida per cinc cobles de vuit versos més tornada de quatre. Les dues poesies restants són cançons paral-lestístiques d'estil popular i tradicional, anònimes, que devien arribar al traductor per transmissió literària

12 Les quatre poesies foren reproduïdes per C.B. BouRL LAND, op. cit, pp. 199202; Johan BOCCACI, Decameron (1429), ed. cit. de J. Mass6 Torrents, pp, 61, 354346, 380, 504-505; A. PAGÉS, «Les poésies lyriques de la traduction catalane du Décaméron», Annales du Midi XLVI (1934), pp. 203-214. Les dues cançons de caràcter popular i tradicional foren editades i estudiades per mi dins el treball $\alpha E l$ cantar paralelístico en Cataluñan, Anuario Musical IX (1954), pp. 46-48, i són les úniques que reprodueix M. MEnÉndez PELAyo, Origenes, cit., II, pp. VII ss.

13 Els fragments de les set cançons indicades han estat reproduits, a ratlla seguida i sense estudi, per C.B. Bourland, op. cit., p. 30; ed. cit. de J. Massó Torrents, p. 344; i M. DE RIQUER, Història, cit., p. 470, nota 67.

14 Veg. M. MuA I Fontan.l.s, «Poètes lyriques catalans», Rerue des Langues Romanes XIII (1878), pp. 18, i dins Obras completas III, Barcelona 1890, p. 457. El text definitiu de la poesia ha estat fitxat per I. CLUZEL, «Princes et troubadours de la maison royale de Barcelone-Aragonn, Boletín de la Real Academia de Buenas Letras de Barcelona XXVII (1957-1958), pp. 369-373, especialment p. 371. 
o bé oral, mentre que les set cançons anunciades per Dioneo són, sense cap mena de dubte, de procedència oral i de transmissió i context folklòrics. Tot seguit ens ocuparem, doncs, de les dues peces paral-lelístiques i dels set fragments folklòrics.

\section{Les dues cançons paral-lelístiques}

Aquestes peces es caracteritzen, a part el seu estil popular i tradicional, per la tècnica amb què estan construïdes: la del paral-lelisme versificatori i estròfic. Coneguda ja pel trobador catala Cerverí pels volts de 1269 , sota la qual redactà el poema que titulà Viadeyra, i enregistrat aquest gènere sota la forma viadera i viandela pels tractas poètics del manuscrit 129 de Ripoll, de l'Arxiu de la Corona d'Aragó, les tolosanes Leys d'Amors i el Torcimany del barceloní Lluís d'Averçó, la tècnica indicada dóna la forma i la pauta a un bon nombre de poemes catalans d'estil tradicional que s'estenen des del trobador esmentat fins a espècimens del segle XVI, amb alguna reminiscència recollida encara a mitjan segle següent ${ }^{15}$. Deixant al marge el seu probable origen, que podem situar en l'escola poètica gallego-portuguesa medieval, aquesta modalitat versificatòria i estròfica, els productes poètics de la qual a Catalunya foren coneguts, insistim, amb el nom de viaderes $\mathrm{i}$, pel que sembla, alguna vegada viandeles, és complexa i de mecanisme complicat i subtil. La cançó paral-lelística hispànica pot constar o no d'un refrany en cap, però la viadera catalana en fa ús pràcticament sempre. Segueixen el refrany dues sèries de petites estrofes de dos i de tres versos isosil-làbics, però també anisosil-làbics algunes vegades, seguits de la repetició d'algun o d'alguns versos del refrany, amb una rima pròpia per a cada sèrie, que a voltes pot ésser assonant. Cada sèrie originàriament era cantada per un cor de veus, i els dos cors

15 Veg. el meu estudi i edició dels textos poètics paral-lelístics catalans o viaderes, «El cantar paralelístico en Cataluña», cit., pp. 7-55. Del manuscrit 129 de Ripoll hi ha edició recent a cura de L. BADIA, Poesia catalana del segle XIV. Edició i estudi del *Cançoneret de Ripollw, Edicions dels Quaderns Crema, Barcelona 1983. 
s'alternaven en el cant de la composició poètica. Els versos de les estrofes de la segona sèrie són variants paral-lelístiques dels de l'altra sèrie, per sinonímia verbal o conceptual, però també per transposició dels mots o per similitud o contrast, i amb canvi de rima, de manera que les estrofetes de la segona sèrie deriven successivament de les de la primera i se singularitzen per la rima pròpia. A les viaderes d'estrofes de tres versos, les dues sèries consten només de dues estrofes. Però a les d'estrofes de dos versos, aquestes s'enllacen entre elles, a cada sèrie, mitjançant la repetició d'un vers, de manera que cada estrofa és constituïda per la repetició del segon vers de l'anterior seguida d'un vers nou, i així successivament. Finalment, cada estrofa d'una sèrie ha d'alternar amb la corresponent de l'altra sèrie, recurs sovint no tingut en compte pels cantaires ni pels copistes. Així, doncs, la presència de refrany en cap, l'existència de dues sèries estròfiques, dotades d'una rima diferent cadascuna, el paral-lelisme dels versos i les estrofes entre les sèries, la repetició del segon vers d'una estrofa al començ de la següent, on es completa amb un de nou, i l'alternança de les estrofes d'una sèrie amb les corresponents de l'altra, caracteritzen, en els seus exemples més purs, la forma externa i el mecanisme versificat i estròfic de la viadera catalana, la qual constitueix una modalitat de la cançó paral-lelística d'origen gallego-portuguès, que, d'altra banda, també fou adaptada per la poesia castellana. La temàtica, variada, és la pròpia de la poesia popular i tradicional, de transmissió oral o literària. Com ho és l'estil, molt concís i sintètic, al-lusiu, referent i expressiu. La forma de discurs dóna també personalitat a la viadera, per tal com el nucli conceptual i temàtic sintetitzat en el refrany es va desenrotllant $\mathrm{i}$ desdoblant en les estrofetes paral-lelístiques $\mathrm{i}$ alternades d'una manera lenta i reiterativa, per mitjà del curs de dos meandres glossadors que insisteixen en els continguts, i les formes i s'interfereixen morosament fïns al desenllaç final, que rubrica l'exposició poemàtica amb un vers concloent dotat d'expressivitat poètica i conceptual.

La viadera del final de la jornada VI fa com segueix:

No puch dormir soleta, no.

Què'm faré, lassa,

si no mi spassa?

Tant mi turmenta l' amor! 
I Ay amich, mon dolç amich!

Somiat vos he esta nit.

Què'm faré, lassa?

II Somiat vos he esta nit que-us tenia en mon lit. Què'm faré, lassa?

III

Ay amat, mon dolç amat!

Anit vos he somiat.

Què.m faré, lassa?

IV

Anit vos he somiat que-us tenia en mon braç. Què $m$ faré, lassa?

Aquesta viadera és formada per un refrany de quatre versos de desigual mesura i per quatre dístics rubricats per un vers del refrany, sempre el mateix. Com no és infreqüent en el gènere, aquí hi ha anisosil-labisme en el vers 1 , i són assonants les rimes dels ver$\operatorname{sos} 1,4,5$ i 15. L'esquema formal de la peça fa així: a'8 $B^{4} b^{4}$ a'7 $-c^{7} C^{7} B^{4} / / C^{7} c^{7} B^{4} / / d^{7} D^{7} B^{4} / / D^{7} d^{7} 7 B^{4}$. Notem que els dístics de les sèries apareixen copiats seguits - I i II, de la primera sèrie, i III i IV, de la segona - i que, per consegüent, no ha estat respectada l'alternança estròfica, que exigeix l'ordre I, III, II i IV. Les rimes paral-leles sinonímiques són d'una extrema simplicitat: amich - amat i lit - braç - la idea de repòs i erotisme relaciona els dos termes-, i notem que el paral-lelisme dels versos es resol un cop mitjançant la transposició dels vocables de la frase: "Somiat vos he esta nit " «Anit vos he somiat».

És poesia posada en boca femenina, un recurs molt antic $\mathrm{i}$ universal, que desenrotlla d'una manera planera i emotiva el tema, així mateix arcaic i generalitzat, de l'insomni amorós de la solitària enamorada que enyora l'amic absent, amb que ha somiat la nit passada en la seva adolorida soledat, i que ha cregut tenir als braços. Tant el recurs com el tema són molt freqüents en la poesia popular i tradicional.

La present viadera ha d'ésser, sens dubte, força anterior a 1429 , i devia haver arribat al traductor per transmissió escrita o per tradició oral. 
L'altra viadera, la del final de la jornada VIII, duu el text següent:

Pus que vuyt jorns stich, senyora, que no.us mir, ara és hora que me'n tolga lo desir.

I E quant eu pas per la posada, eu dich: - Amor, qui-us ha lunyada que no us mir? Ara és hora que me'n tolga lo desir:-

II Yo dich: - Amor, qui-us ha lunyada?

- Lo falç marit, qui-m ha reptada que no-us mir: Ara és hora que me'n tolga lo desir:-

III E quant eu pas per la partida. eu dich: - Amor, qui-us ha trahida que no.us mir?

Ara és hora que me'n tolga lo desir:-

IV Yo dich:- Amor, qui-us ha trahida?

- Lo falç gelós, qui-m ha ferida que no.us mir.

Ara és la hora que me'n tolga lo desir -

Com l'anterior, aquesta viadera és formada per un refrany de quatre versos de desigual extensió i per quatre dístics, aquí seguits, cadascun, pels tres versos finals del refrany. Els versos, de vuit i tres síl-labes, són isosil-làbics, i la rima és consonant, llevat dels casos dels versos 1 i 3 i la repetició d'aquest al final de les estrofes. El paradigma formal fa com segueix: $a^{7} \mathrm{~B}^{3} A^{7} \mathrm{~B}^{3}-c^{8} C^{8} \mathrm{~B}^{3} A^{4}$ $\mathrm{B}^{3} / / C^{8} c^{8} \mathrm{~B}^{3} A^{7} \mathrm{~B}^{3} / / d^{8} D^{8} \mathrm{~B}^{3} A^{78} \mathrm{~B}^{3} / / D^{8} \mathrm{~d}^{8} \mathrm{~B}^{3} A^{18} \mathrm{~B}^{3}$. Com a la viadera anterior, els dístics de les dues sèries han estat copiats seguits - I i II, corresponents a la primera sèrie, i III i IV, corresponents a la segona-, de manera que a la present tampoc no s'ha respectat l'alternança estròfica, que exigeix la seqüencia I, III, II i IV. Les rimes paral-lelístiques són clares en posada i partida, mots si- 
nonímics que comporten idea de lloc i situació, mentre que lunyada i trahida, i reptada i ferida, també sinonímics, ho són per extensió i derivació semàntica del primer concepte.

La nostra viadera desenrotlla un diàleg entre l'amant i la malmaridada. Ell passa davant la casa d'ella amb l'esperança de veure-la i d'estar junts, i la malmaridada li exposa la seva queixa que el marit, lo falç gelós, l'ha reptada i ferida perquè no el vegi. El tema de la requesta a la casada $\mathrm{i}$ el de la malmaridada que el marit desconsiderat $i$ gelós reprèn o fins $i$ tot bat, són ben coneguts de la poesia popular i tradicional antiga i del folklore actual, i presenten diversitat de variants i modulacions.

Aquesta viadera, pervinguda, com l'altra, al traductor català del Decameron per tradició escrita o bé oral, o escrita i oral al mateix temps, també ha d'ésser força anterior a 1429. Ho provaria, a més, la presència de la forma $e u$ per al pronom de primera persona del singular que veiem als versos $5,6,15 \mathrm{i} 16$, alternant amb la forma habitual yo, dels versos 10 i 20.

\section{Les cançons de Dioneo}

Al final de la jonada $\mathrm{v}$, llegim, a la traducció catalana de 1429 . el text següent, del qual destaco els fragments poètics que hi són esmentats i escrits a ratlla seguida:

E havent ja, ab voler de la reyna, presa una dança Emiltia, fo comandat a Dioneo que cantàs una cançó. Lo qual prestament comensà:

$$
\begin{aligned}
& \text { [1] - Si.m trobau al bosch soleta, } \\
& \text { sol, sol no me' } n \text { demandeu. }
\end{aligned}
$$

De la qual totes les dones comensaren fortment a riure, e majorment la reyna, la qual li comandà que lexàs aquella cançó e que $n$ digués una altra. A la qual dix Dioneo:-Senyora, si yo hagués lo meu temboret, yo diguera:

[2] Dejús lo formatge fresch bona m'és l' amor.

¿O si volguésseu que digués:

[3] E la tum tum vitarda, o diguera:

[4] Vitum vitayna 
la calorete $m$ ve?

¿O volríeu que digués:

[5] En Burell m'à vist lo cony, mesquina!?

Mas yo no he lo temboret, e axi vejau vós qual voleu que vos diga. D'aquestes, plau-vos-ne alguna? Si no, feu-vos-ne tallar una al bosch.

- Vé - dix la reyna - digues-ne una altra, bona.

-Donques - dix Dioneo-, ¿voleu que diga.

[6] Vayandano, vayandó, vayandana mia?

Lavors la reyna, rient, li dix:

-Vé en mala hora! Digues-ne una bona, car nosaltres no volem de aquexes.

Dix lavors Dioneo:-Madona, no.us doneu despler d' açò, car yo diré aquella que vós volreu, car yo-n scé més de mil. Per què, si voleu que diga:

[7] - Ay marit! Com no:m ho feu, per pauch no·m feu Déu descreure.

yo la diré.-

Per Déu, dona, no-us cuyteu!,

La reyna, donchs, fellona, posat que les altres se'n riessen, dix:

- Dioneo, lexa star lo motejar e digues-ne una qui sia bella, sinó yo.t poria mostrar yo com me scé enfellonir.

Les cançons que canta Dioneo en la versió del Decameron de 1429 pertanyen sens dubte a la tradició oral i folklòrica de la Catalunya de la segona meitat del segle XIV i la primera del següent. El traductor se'n valgué per anostrar la seva labor, tot substituint les de l'original toscà del mateix gènere, les quals, aillades del context corresponent i hipotèticament desdoblades, la majoria, en forma versificada, són aquestes:

Monna Aldruda, levate la coda, ché buone novelle vi reco.

Alzatevi i panni, monna Lapa.

Sotto l' ulivello è l'erba.

L'onda del mare mi fa si gran male.

Escici fuor che sia tagliato, com' un mio in su la campagna. 


\section{Monna Simona imbotta imbotta. $e^{\prime}$ non è del mese d'ottobre.}

Questo mio nicchio

s'io nol picchio.

Deh fa pian, marito mio.

Io mi comperai un gallo

delle lire cento. 16

Les cançons catalanes cantades per Dioneo en la traducció es caracteritzen, ultra la seva acusada i clara tradicionalitat popular i folklòrica, per la seva agilitat, concisió i expressivitat estilístiques, tan pròpies del gènere, i pel contingut eròtic, intencionat i maliciós de gairebé la totalitat d'aquestes, 0 , amb més precisió, les de text amb contingut conceptual suficientment exprés. Dues de les set peces, la [3] i la [6], constitueixen únicament refranys-bagatel-la sense sentit semàntic, reduits a successions rítmiques i foniques i molt apropiats per al ball i la dansa ${ }^{17}$. La [4], d'altra banda, és la síntesi d'un vers de refrany-bagatel-la i un altre amb contingut conceptual precís, de suggeriments eròtics. Cadascuna de les altres cançons, i també la [4], fa el seu sentit puntual i clar, expressat en frases sintàctiques inequívoques, sempre amb la mateixa intencionalitat $\mathrm{i}$ abast eròtics, indicats sense eufemismes. La [1] i la [5] són clarament cançons femenines, i tal vegada ho són també les altres, llevat de la [7], que és un diàleg desenfadat i directe entre muller i marit.

Les set peces catalanes pertanyien sens dubte a cançons de dansa, i devien ésser refranys de peces dansades més extenses. Notem que la cançoneta [1] és interpretada durant la dansa que inicia Emília, i que les altres havien d'ésser cantades al so del temboret que

16 Extrec els textos poètics de Giovanni Boccaccio, Opere, a cura de Cesare Segre, U. Mursia \& C., Milà $1966^{3}$, pp. 388-389.

17 Sobre aquest gènere, veg. el meu estudi «A la tonada de la Guilindó. Naturalesa i fortuna d'un refrany-bagatel-la $(1792) »$, reproduit dins el meu recull $P_{O}$ esia popular i literatura, Curial, Barcelona 1974, pp. 13-72. 
Dioneo en aquells moments diu que no té a mà. A més, ja hem dit que [3] i [6] són refranys-bagatel-la, gènere que era interpretat en cançons dansades, i que [4] n'és un compost, sens dubte amb la mateixa finalitat. Les altres peces segurament eren refranys en cap de cançons de dansa més extenses, que els glossaven al llarg de la composició.

Totes aquestes petites peces constitueixen, en definitiva, un testimoni molt valuós de la poesia popular, tradicional i folklòrica de la Catalunya de la segona meitat del segle XIV i dels primers decennis del $\mathrm{XV}$. 